Viso - Cadernos de estética aplicada Revista eletrônica de estética

ISSN 1981-4062

$N^{\circ} 23$, jul-dez/2018

http://www.revistaviso.com.br/
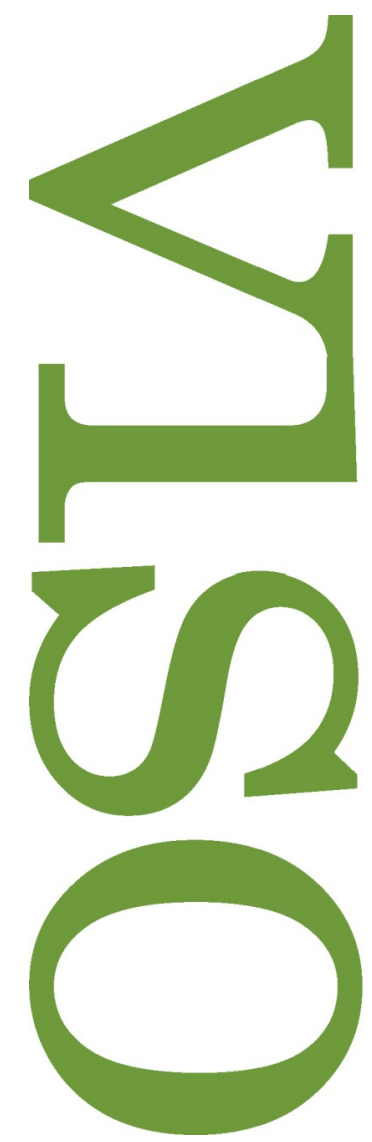

\title{
A sociabilidade eletrônica e a tela total Pedro Süssekind
}




\section{RESUMO}

A sociabilidade eletrônica e a tela total

Esse artigo é uma réplica ao texto de Bernardo Barros Oliveira intitulado "Por que narrativas de ficção no mundo da sociabilidade eletrônica?".

Palavras-chave: narrativa - ficção - informação - redes sociais

\section{ABSTRACT}

Electronic Sociability and Total Screen

This paper is a critical response to Bernardo Barros Oliveira's "Why Fiction Narratives in the World of Electronic Sociability?".

Keywords: narrative - fiction - information - social networks 
SÜSSKIND, P. "A sociabilidade eletrônica e a tela total". In: Viso: Cadernos de estética aplicada, v. XII, n. 23 (juldez/2018), pp. 266-274.

DOI: $10.22409 / 1981-4062 / v 23 i / 266$

Aprovado: 19.10.2018. Publicado: 27.12.2018.

(ㄷ) 2018 Pedro Süssekind. Esse documento é distribuído nos termos da licença Creative Commons Atribuição-NãoComercial 4.0 Internacional (CC-BY-NC), que permite, exceto para fins comerciais, copiar e redistribuir o material em qualquer formato ou meio, bem como remixá-lo, transformá-lo ou criar a partir dele, desde que seja dado o devido crédito e indicada a licença sob a qual ele foi originalmente publicado.

Licença: http://creativecommons.org/licenses/by-nc/4.0/deed.pt_BR

Accepted: 19.10.2018. Published: 27.12.2018.

(C) 2018 Pedro Süssekind. This document is distributed under the terms of a Creative Commons Attribution-NonCommercial 4.0 International license (CC-BY-NC) which allows, except for commercial purposes, to copy and redistribute the material in any medium or format and to remix, transform, and build upon the material, provided the original work is properly cited and states its license.

License: http://creativecommons.org/licenses/by-nc/4.0/ 
Antes de fazer um comentário do texto "Por que narrativas de fiç̧ão no mundo da sociabilidade eletrônica?", gostaria de começar com duas observações e um exemplo. A primeira observação é que considero um prazer discutir um trabalho que propõe um diagnóstico de aspectos determinantes do mundo contemporâneo. A segunda é que o diagnóstico afeta pessoalmente a cada um de nós. O exemplo que me ocorreu tem a ver com essa dimensão pessoal do texto e diz respeito a uma experiência que vivi dois anos atrás.

Por sorte, em 2016, ganhei um convite para ir ao evento mais concorrido dos Jogos Olímpicos do Rio: a final da corrida de cem metros rasos, na qual o atleta jamaicano Usain Bolt tinha a chance de encerrar sua carreira em Olimpíadas com a terceira medalha de ouro e assegurar o seu nome como o maior velocista na história do atletismo. Evidentemente, esse evento esportivo recebeu grande destaque da mídia e teve uma audiência de centenas de milhões de pessoas mundo afora.

A princípio, o que me parecia inusitado nesse evento específico que tive a sorte de presenciar era a sua duração, já que a corrida de cem metros rasos ocorre em menos de dez segundos. Há uma estranha desproporção entre essa rapidez e a magnitude do acontecimento. As imagens desses dez segundos de atividade, documentadas por centenas de câmeras de tevê de todos os ângulos possíveis, seriam repetidas exaustivamente pelas emissoras de tevê e ficariam disponíveis na internet para qualquer pessoa interessada. Jornalistas e comentaristas esportivos dos mais diversos países escreveriam ou falariam sobre a vitória de Bolt. Mas, em comparação com esse acesso ao acontecimento por meio da cobertura jornalística, a diferença de assistir à corrida no estádio diz respeito a uma outra vivência dessa dimensão temporal de expectativa e intensidade. As pessoas nas arquibancadas do estádio passam horas esperando e assistindo a outras provas, até chegar o momento mais aguardado. Além disso, como um sinal inequívoco da importância desse momento, o espectador tem a experiência de fazer parte da plateia imensa e ruidosa que, antes da largada, fica completamente em silêncio.

Pois bem, nessa situação que parecia ser de uma atenção totalmente concentrada no que acontecia ao vivo, o que me surpreendeu foi notar que muitas pessoas na plateia sacaram seus celulares e filmaram a corrida. Com isso, elas trocaram, pelo menos em parte, a experiência direta e ao vivo por uma outra experiência, de observar aquele evento único de dez segundos na tela do celular. E quem fez isso sabia que aquele evento já estava sendo filmado de todas as maneiras possíveis, por centenas de câmeras.

Considerei essa troca muito difícil de explicar e certamente um sinal dos nossos tempos. Mas só agora, dois anos depois, lendo o texto de Bernardo Barros Oliveira, consegui entender melhor o significado daquele gesto que eu tinha presenciado. 
"Por que narrativas de ficção no mundo da sociabilidade eletrônica?", texto que passo a comentar agora, avalia um tipo de comportamento cada vez mais comum, que diz respeito a uma redefinição tanto das nossas relações sociais, quanto da nossa percepção ou sensibilidade. A expressão "mundo da sociabilidade eletrônica", no título, me parece dialogar com a "era da reprodutibilidade técnica", do conhecido ensaio de Walter Benjamin sobre a arte de seu tempo. ${ }^{1}$ Além disso, a reflexão formulada sob aquele título dialoga com uma série de diagnósticos a respeito das formas narrativas formulados em outros ensaios do mesmo autor, como "Experiência e pobreza" e "O narrador". ${ }^{2}$ Esses ensaios, escritos na década de 1930, propõem uma teoria da narrativa que pretendia explicar as mudanças na experiência humana e em sua transmissão ocorridas no início do século vinte, com o advento e o predomínio da informação jornalística sobre as formas mais tradicionais de narrar os acontecimentos.

Entretanto, a intenção do texto que comento aqui não foi a de repensar os fenômenos que o próprio Benjamin observava cem anos atrás, e sim de comparar seus diagnósticos com fenômenos atuais e com uma transformação social típica do mundo contemporâneo. Considero que essa intenção pode ser resumida assim: Se o predomínio da informação jornalística nas primeiras décadas do século vinte levou Benjamin a diagnosticar o empobrecimento da experiência e a crise da narrativa, qual seria o diagnóstico agora, diante deste "mundo da sociabilidade eletrônica" em que vivemos?

Para se chegar a uma resposta a essa pergunta, serve como ponto de partida uma experiência concreta narrada pelo autor. Bernardo Barros Oliveira fala de um princípio de incêndio que ele presenciou ao andar pela rua, um acontecimento que estava sendo registrado nos celulares dos demais passantes, aparentemente muito mais interessados na repercussão dessa cena pitoresca em suas redes sociais do que no evento em si. Essa observação leva ao diagnóstico de uma modificação na sensibilidade que faz as pessoas se comportarem como "repórteres de prontidão", fornecendo imagens de qualquer acontecimento público ou privado que seja julgado interessante para os olhares dos outros. Assim, o que as câmeras dos celulares captam é "a performance de um sujeito" que não só "se autoproduz como espetáculo", mas também "que estuda cuidadosamente seus próprios gestos e seu entorno no intuito constante de estar presente para o olhar do outro que, ao aplaudi-lo, atestará o sucesso e efetividade da performance". ${ }^{3}$

Evidentemente, não nos faltam exemplos desse tipo de comportamento em cenas da vida real observadas a qualquer hora, em restaurantes, em festas, em espetáculos, ou em passeios pelas ruas. Afinal, quem nunca viu duas pessoas sentadas para jantar interromperem a conversa (se é que houve alguma) e permanecerem em silêncio com os olhos grudados nas telas de seus celulares, checando suas mídias sociais? Basta pensar também no público de exposições de arte que abre mão de observar as obras diretamente e, em vez disso, passa a tirar fotos delas para exibir nos perfis dessas mídias. Já nos shows de música, muitas vezes nós espectadores temos dificuldade em 
assistir ao que se passa no palco porque ele é parcialmente tampado pelas telas estendidas para o alto, nas quais brilham as diversas pequenas imagens daquele palco que tentamos enxergar.

Portanto, a abordagem de diagnósticos benjaminianos, no texto "Por que narrativas de ficção no mundo da sociabilidade eletrônica?", diz respeito a uma comparação, não a uma análise da situação que despertou aqueles diagnósticos. O que se observa é uma intensificação e exponenciação dos elementos problemáticos enxergados no predomínio da informação jornalística, que desde o início do século vinte já convertia os acontecimentos em fatos para consumo imediato. Só que atualmente não se trata mais de um público de leitores de jornal que restringe seu interesse a fatos comprováveis e recentes, relatados por repórteres, mas de um público de leitores de redes sociais que é, ao mesmo tempo, o público de geradores das miríades de acontecimentos que, nessas redes, são convertidos em informações disponíveis vinte e quatro horas por dia.

As consequências desse tipo de comportamento são multifacetadas. Uma delas é que todos nós vivemos num mundo bombardeado incessantemente por imagens que se desdobram nas telas dos computadores, das tevês e dos celulares. Essas imagens, filtradas pelos interesses da mídia ou pelos algoritmos das redes sociais, incluem o registro de todo gênero de acontecimentos ocorridos em qualquer lugar do mundo.

Jean Baudrillard cunhou para esse fenômeno da profusão de imagens no ambiente contemporâneo o nome de "tela total". ${ }^{4}$ Analisando a presença constante do computador, vídeo, televisão ou celular em nossas vidas, o filósofo francês procurou mostrar, em seu livro Simulacros e simulação, de 1981, que as imagens predominantes em nossa sociedade da hipervisibilidade podem ser caracterizadas como simulacros nos quais os próprios eventos não constituem experiências e mal são registrados na memória. ${ }^{5}$

O historiador alemão Hans Belting também analisa esse fenômeno no livro $O$ fim da história da arte, cuja primeira versão é de 1983. Segundo ele, em um diagnóstico muito semelhante ao de Baudrillard, a revolução digital teria criado uma espécie de "tela onipresente", na qual o acervo infinito de imagens disponíveis online produz o fantasma de uma presença absoluta. ${ }^{6}$ Trata-se, assim, do problema contemporâneo do excesso de imagens que preenchem o mundo, a ponto de dissolver os limites entre o que é real e o que é virtual. Como consequência, seria preciso levar em conta, na avaliação da arte e de sua história, o contexto no qual as mídias técnicas determinam a imagem que fazemos do mundo.

Em sua reflexão sobre esse assunto, ao considerar a relação das artes com as mídias no mundo atual, Belting retoma justamente as ideias de Walter Benjamin. Seu livro sobre o fim da história da arte remete especificamente à noção benjaminiana de perda da aura, formulada no ensaio sobre a obra de arte na era de sua reprodutibilidade técnica. Isso porque Belting considera que, na arte multimídia contemporânea, a presença do objeto 
artístico é substituída por impressões adaptadas ao caráter fugaz da percepção atual. ${ }^{7}$ Ele comenta: "No fundo, trata-se ainda da velha questão benjaminiana acerca do significado da arte no mundo técnico e de como ela se modifica nessa era". ${ }^{8}$

Segundo a análise do mundo contemporâneo proposta por Bernardo Barros Oliveira, duas características se destacam nessa sociabilidade marcada pela avalanche de imagens do mundo digital. A primeira é que os indivíduos se tornaram ao mesmo tempo leitores, personagens e produtores de informações, "e também, espectadores uns dos outros". ${ }^{9}$ A segunda é que não existe mais fronteira entre o público e o privado, de modo que qualquer coisa pode ser compartilhada, mesmo os detalhes mais íntimos e pessoais, contanto que desperte a aceitação traduzida em "curtidas" por parte dos integrantes da sua rede social.

A questão central do texto é relacionar esse mundo da sociabilidade eletrônica com o problema da narrativa, uma vez que "os novos hábitos, criados e cultivados durante o intensivo e extensivo contato com telas online, contrasta fortemente com tudo o que foi lentamente criado e cultivado durante a longa história da construção da prosa longa e sua tecnologia básica, o livro". ${ }^{10}$

Parece haver uma tendência de substituir as narrativas tradicionais (histórias e relatos escritos) por uma espécie de má ficção sob a ótica da informação e da criação de celebridades. Segundo esse raciocínio, consumimos e produzimos as mais variadas narrativas midiáticas elaboradas com os registros que incluem pratos consumidos em restaurantes, lugares visitados em viagens, pequenos acontecimentos pitorescos, visuais deslumbrantes, cenas curiosas de crianças e animais de estimação, mas também notícias destacadas da grande mídia ou divulgações de eventos variados. Essas narrativas têm como personagens os próprios integrantes da rede social eletrônica

Uma consequência importante desse acervo incomensurável de registros imagéticos variados e imediatamente disponíveis diz respeito ao seu uso político e publicitário. O texto em questão aqui faz uma breve análise dessa consequência comentando tanto as chamadas fake news, quanto as bolhas geradas pelo nosso hábito de selecionar os integrantes da rede social por compatibilidade de interesses e posicionamentos. Seu diagnóstico é o de que "o mundo em que se vive hoje já não tem traços gerais e comuns". Desse modo, "cada um vive no raio de realidade do que é plasmado em sua rede social", onde circulam "as informações que definem o que é e o que deve ser o real". 11

Retomando a associação proposta entre vida social e maneiras de narrar os acontecimentos, resta saber então se, neste nosso mundo da sociabilidade eletrônica, ainda há espaço para as formas narrativas ficcionais escritas ou audiovisuais, cuja recepção foi tradicionalmente um "hábito cultural de longa história", ligado à possibilidade 
de aprender com a experiência alheia e olhar as coisas com perspectivas novas, portanto de sair por um momento do universo já conhecido.

A resposta para esse questionamento passar por uma reflexão sobre o papel que as narrativas ficcionais de larga circulação e influência cultural, em especial as séries televisivas, podem ter para "retirar momentaneamente cada um de seus feudos online de má ficção e trazer para algum resquício de espaço público". ${ }^{12}$

Assim, para relacionar o mundo da sociabilidade eletrônica com a questão da narrativa, seria preciso tentar entender o grande impacto de alguns dos produtos mais refinados da indústria cultural. A meu ver, essa tentativa impõe pelo menos três tarefas diferentes para o crítico da cultura.

A primeira delas é formal: responder se existe ou não um nexo entre a lógica do consumo de imagens das redes sociais e o formato serial tanto dos produtos de cultura de massas, quanto de vertentes atuais da literatura. Um nexo desse tipo poderia justificar o interesse por obras de ficção especialmente longas e de enredos complexos.

A segunda tarefa é semiológica: decifrar os signos de um produto cultural específico a fim de compreender a sua absorção na vida cultural como uma maneira de dar voz a certas demandas, problemas ou obsessões do mundo contemporâneo. Seria o caso, por exemplo, de analisar as distopias propostas em episódios de Black Mirror, ou de explicar nosso fascínio obsessivo por mortos que voltam do túmulo e interpretar quem são os zumbis de Walking Dead ou de Game of Thrones.

Ao que parece, a sociabilidade eletrônica, com sua lógica da fugacidade e da superficialidade, convive com um interesse por formas narrativas longas e bastante elaboradas. Agora, será que em nossa sociedade a elaboração ficcional de narrativas tende a passar totalmente para o campo audiovisual? Ou a ficção ainda continuará a acontecer também em livro, no campo mais tradicional da literatura? Bernardo Barros Oliveira menciona exemplos de romances contemporâneos que desenvolvem enredos longos e complexos, como os de Murakami e Jonathan Franzen, e que despertam grande interesse de um público de leitores que habitam as redes sociais.

Levando em conta essas questões, um terceiro esforço crítico, associado aos dois anteriores, diz respeito a uma reflexão sobre as formas artísticas que têm, hoje, justamente a capacidade de expressar e pôr em questão o mundo da sociabilidade eletrônica.

\footnotetext{
* Pedro Süssekind é professor do Departamento de Filosofia da UFF.

${ }^{1}$ Cf. "A obra de arte na era de sua reprodutibilidade técnica". In: BENJAMIN, W. Benjamin e a obra de arte. Rio de Janeiro: Contraponto, 2012, p. 52.
} 
${ }^{2}$ Cf. Idem. Obras escolhidas, v. 1. São Paulo: Brasiliense, 1985.

${ }^{3}$ BARROS OLIVEIRA, B. "Por que narrativas de ficção no mundo da sociabilidade eletrônica?".

${ }^{4}$ O tema já trabalhado em Simulacros e simulação, de 1981, foi reelaborado no livro Tela total: mito-ironias da era virtual e da imagem, publicado em 1997. Cf. BAUDRILLARD, J. Simulacres et simulation. Paris: Galilée, 1981; Tela total: mito-ironias da era virtual e da imagem. Porto Alegre: Sulina, 1997.

${ }^{5}$ Idem. Simulacro e simulação. Lisboa: Relógio d’água, 1991, p. 56.

${ }^{6}$ BELTING, H. O fim da história da arte. São Paulo: Cosacnaify, 2012, p. 284.

7 Ibidem, p. 31.

${ }^{8}$ Ibidem, p. 289.

${ }^{9}$ BARROS OLIVEIRA, B. Op. cit.

${ }^{10}$ Ibidem.

${ }^{11}$ Ibidem.

12 Ibidem. 